\title{
Concepts Only Please! Innovating A First Year ENGINEERING COURSE
}

\author{
Kenneth N. McKay, Samar Mohamed, and Lyndia Stacey \\ Faculty of Engineering, University of Waterloo, Ontario, Canada \\ kmckay, samar.mohamed, lestacey @uwaterloo.ca
}

\begin{abstract}
MSCI 100, a first year course dedicated to Management Engineering, introduces the main concepts of this discipline to students in their first term. The course's main goals are introducing core principles that students will apply throughout their undergraduate studies and also preparing them for their first cooperative education term. In Fall 2015, this course was pedagogically redesigned based on authentic selfdirected learning, accommodating different learners, and providing students with opportunities to develop professional skills (especially teamwork, project planning, time management and critical thinking).

The course was designed holistically with emphasis on integrating concepts and communicating the course plan to students. Although engineering design was an inherent part of the course, there were no memory-driven tests and no math. The course's learning outcomes were instead formulated around students' understanding of improving effectiveness and efficiency in various facets of business through the development of their professional skills.

There were numerous teaching innovations from the perspective of a first year engineering course. The essence of many course deliverables was for students to experience constructive failure-recovery cycles. This allowed them to learn from their mistakes as they completed case study challenges, hands-on activities, unique assessments and a final team project requiring integration of knowledge and skills. These activities were supported by various groups on campus.

A panel of educators was formed near the end of the term so students could reflect on their learning process and be provided with the educators' feedback. Moreover, the results from the course evaluations indicated that the restructuring of MSCI 100 was largely successful. Most students were able to fully grasp fundamental concepts and apply critical thinking skills. In this paper, we share reasons for redesigning the course, our experience in delivery and assessment, the impact of different teaching and learning methods and finally feedback on switching to in-depth, student-centered learning.
\end{abstract}

Keywords: first year engineering, self-directed learning, professional skills, failure-recovery cycles, management engineering

\section{INTRODUCTION}

The thought-provoking challenge of introductory engineering courses is knowing how to effectively expose students to major concepts in their newly established discipline. There is a precarious balance between breadth and depth such that the course is neither convoluted nor boring [1]. This first exposure to the discipline must create a highly exciting impression on the students that instills academic motivation [1]. In addition, its role is to also fill gaps in academic backgrounds [2].

These introductory courses often compartmentalize the various concepts which limit the students' ability to synthesize and solve engineering problems. There is an illaimed goal of imparting pure knowledge and it is usually assumed that a set of rules must be memorized before a student can analyze or apply concepts. This can be pervasive in the educational system which suggests to students that learning is the same as memorization [2].

If you further reflect upon the introductory courses found in traditional 20th century industrial engineering programs, the same basic pattern of content and delivery has been largely left unchanged for the past century. We call this traditional design second-order at the conceptual level because it assumes that students have sufficiently mastered problem-solving and analysis. In this traditional style, another implicit assumption is that the students know how to work in teams and ultimately have an adequate foundation in professional skills.

\subsection{Professional Skills Foundation}

Professional skills and communication in introductory courses should be taught within the context of the specific discipline [1]. If this happens right away in first year, students are set-up with a foundation that will lead to 
higher performance in future courses. These skills are typically taught implicitly in engineering programs and students are expected to graduate with fully formed professional skills [1]. However, there are advantages of explicitly focusing on this skill-set.

It cannot be assumed that all students have an equal foundation in professional skills; nor can it be assumed that students are satisfactorily prepared to begin undergraduate studies. Perhaps the biggest implicit assumption that instructors make is that the students understand how to systematically think! These skills all vary based on factors of gender, ethnicity, preparation and prior experience. Essentially, a wide spectrum of skills is brought to a first year introductory course [3]. With this diversity, an instructor must be prepared for students to develop this skill-set through many mistakes.

\subsection{Advantages of Mistakes}

Learning from mistakes is not inherent to engineering, but to being human. It is far more likely to remember failure than success and this is why it is a great tool in education.

Students tend to characterize mistakes as failure. This is probably because mistakes typically result in a loss, for example failing a test. Mistakes then impact morale, selfesteem, and performance [4]. A change in educational culture needs to occur so that mistakes are instead used to enhance learning. This needs to happen immediately in first year so students know that mistakes are simply a component of their education. A course environment must then be supportive of mistakes and provide opportunities for feedback [4]. Not only that, instructors must provide opportunities to learn, evaluate and apply this feedback (i.e. resubmissions) [1]. This pedagogical outlook was a key cornerstone in the redesign of a first year Management Engineering course.

\subsection{What Is Management Engineering?}

In this paper, we are discussing a "concepts course" for the Management Engineering program at University of Waterloo. First of all, what is Management Engineering? Management Engineering focuses on improving the efficiency and effectiveness of processes and systems, both the systems themselves and what they produce. The discipline is multi- and inter- disciplinary and delves deeply into problem-solving. How can problem-solving be more efficient and effective? How can better decisions be made? How can the tools and methods used for the decision-making be improved? These are all important questions in Management Engineering.

Since the focus is on the efficiency and effectiveness of a task, we look at issues along the journey and not just the final result. This is done using engineering principles, systematic analysis and evidence-based reasoning. In general terms, Management Engineering is the 'make it better' discipline. This implies core skills in the concepts of problem identification, problem and gap analysis, requirements specification, problem-solving, solution creation, solution rationalization, communication, teamwork, project management and change management. We augment these core skills with specific tools and methodologies from Operations Research, Organizational Behaviour, Management of Technology and Information Technology [5].

\subsection{First Year Concepts Course (MSCI 100)}

In the Faculty of Engineering at University of Waterloo, engineering students begin specialization in their first year. In most programs they take common courses in their first term (i.e. calculus, linear algebra, physics and chemistry) along with a dedicated course specific to their discipline. This special four month course (MSCI 100) carries 50\% more weight than a typical course and is called the "concepts course" within the faculty. The definition of concept implies generality, abstractions, notions, and constructs. The goal of this type of course is to introduce the foundational concepts related to the discipline, have students understand these core concepts, help transition the students to post-secondary education and start the students on their journey through the program. This sounds simple.

The first difficulty is with what is meant by a concept: almost anything and everything taught in post-secondary education at all levels can be called a concept. The second difficulty is facilitating the students' ability to actually understand the foundational concepts and then to also demonstrate their level of mastery. This is the 'what' and 'how' challenges associated with designing any concepts course. Furthermore, these concepts must extend to include development of professional skills and systematic thinking. Since rules and principles are much less retained compared to analysis and application (primary functions of an engineer), it should be these areas of focus in a first year concepts course [2].

\subsection{Course Redesign}

A partial review and re-design of MSCI 100 was performed for the fall 2014 offering. There were a number of delivery and execution changes made to see if we could improve the core skills while retaining the traditional structure. Material was reduced and more experiential exercises were added to the course. It was our impression that, while this improved some professional skills, there was room to increase course effectiveness. Our 
Management Engineering graduates are being hired for their problem-solving and analytical skills. We wanted to improve the core skills of the students; to make them even better and more employable in their co-op- terms and upon graduation. This all starts in the introductory course.

A change in instructors provided an opportunity in 2015 to re-visit the course again. The incoming instructor knew the discipline and had expertise in cognitive psychology, specifically in the areas of learning and organizational planning.

During the 2015 implementation of MSCI 100, explicit discussions on how to think and how to approach the unknown were an essential part of the course plan. It was not just one problem or a few examples, but several dozen. Anything and everything seen, heard, or experienced during the course was fair game for analysis. Everything was on the table for self-reflection. Closing the loop was always considered and feedback sessions occurred throughout the term. A longer and more formally structured feedback session was also held at the end of term to discuss the professional skills component of the course.

\subsection{Innovation Needs Support}

The delivery of the newly redesigned course required a great deal of help and planning. MSCI 100 was completely overhauled using a team approach, enlisting help from various groups on campus. This included the Centre for Teaching Excellence (CTE) [6], Student Success Office [7], WATCACE (Centre for the Advancement of Co-operative Education) [8], Engineering IDEAs Clinic [9], and Waterloo Cases in Design Engineering (WCDE) [10]. The main strategy was to focus on the development and mastery of core skills.

The three co-authors of this paper worked as the final push team in the four months before launch to discuss and finalize the flow, pacing, scaffolding, core examples, content and case study design. In reality, parts of the new course design were in the process for two years as various ideas were discussed with approximately a dozen advisors, contributing to an overall structure for the course. A great deal of the design for introducing new pedagogy and assessment methodology to students was informed and influenced by the discussions, background work and doctoral research results of Ellis [11].

During the course, the various groups provided support by participating in a third of the lectures. Without the course 'team', the course style and requirements would have been overwhelming. There were also two full-time undergraduate teaching assistants (specific co-op students hired for the MSCI 100 concepts course). The support team was made transparent to the students and this helped reduce their fear and anxiety. They could see that the journey was not ad hoc and not without conscious design.
Everyone was passionate about helping the students learn to learn, increase problem-solving skills and hone teamwork. We think that this passion and desire were instrumental in student engagement and motivation. The instructors cared. They really cared!

During the term, the various pedagogical methods were also discussed in a transparent way to the students: the rationale was explained and examples were given. These discussions often used cause and effect analyses - using course concepts to teach course concepts. While the students did not fully understand all of the pedagogical methods until they actually experienced them, the students knew that a method was coming and that the method was not an accident: a number of people had been involved in what was about to happen and mechanisms were in place to accommodate mistakes and learning.

\section{FIRST YEAR CONCEPTS COURSE IN MANAGEMENT ENGINEERING}

The Management Engineering program saw the first intake of students in 2007 and we are now, spring of 2016, graduating our fifth cohort. MSCI 100 has been taught a total of nine times with adjustments and course overhauls during this time based on student feedback.

Prior to 2015, the design of MSCI 100 can be described as a second-order type course with regard to concepts. The instruction goals focused on imparting knowledge on what is done in typical Management Engineering tasks and the tools used to perform these tasks. The concepts related to topics such as inventory, supply chains, production systems, assembly, service situations and networks. Analytical tools were introduced that addressed how to quantitatively study these application areas and make them more effective and efficient. The lessons from previous course offerings were used to further refine MSCI 100 for fall 2015.

\subsection{Key Cornerstones of the Course}

The following summarizes sixteen key characteristics of MSCI 100 in fall 2015. Since students are more engaged when they see a clear link between all course concepts, this was attempted with practical and motivating projects [1]. All concepts were integrated for higher student performance [12]. Therefore, the course was designed in a holistic fashion with each of the following characteristics consciously discussed, debated and designed in consideration of all other parts. There was not a single pedagogical method designed to stand on its own.

1. Early assessment of the students' level of selfawareness as well as their ability to write and 
analyze - via an essay at the start of the course on explaining their success in high school.

2. Appraisal of learning styles to determine the mix of learning styles [13] in the classroom and to help the students understand their own style.

3. Teamwork exercise on the first day that highlighted problem solving, communications and systematic approaches.

4. Trial midterm - structured, executed and marked just like a real midterm in the second week of the course to expose and prepare students to what they will encounter at the postsecondary level.

5. Maximum student understanding - all examples and activities were selected so that students would not have to learn the example domain at the same time as the concepts being introduced. The goal was for the students to learn one thing at a time and learn it well.

6. The delivery of key concepts in the course used an introduction, development, and application strategy with multiple learning moments and experiences on each concept - with feedback and progression expectations.

7. Constructive failure mechanisms were used [14] for the majority of concepts and key learning outcomes along with feedback closure. This allowed the students to develop selfconfidence as their skills improved during the course. They were surprised to discover that they could learn and deliver without being 'taught' and without having 'facts' to repeat.

8. Students could resubmit one assignment. The resubmission's rubric was heavily weighted towards how the student responded to the feedback given on the first attempt.

9. Cause and effect lectures on how to approach this type of analysis in a structured fashion (i.e. using KJ [15] and Ishikawa [16] methods).

10. Six assessments were included on the various midterms to provide multiple opportunities for feedback and facilitate students' improvement.

11. Modeling and abstraction lectures were incorporated into the course with assessments on midterms that asked students to create models and receive feedback.

12. There was no memorizing or fact regurgitation. Students were asked to analyze situations using a concept, identify potential cause and effect relationships, justify their analysis, and demonstrate how much they understood the concept. The topics were chosen so that open books and web access were permitted but would not be useful.
13. There were in total six team activities, five of which involved the same team composition. This allowed the students to learn how efficient and effective teamwork comes from multiple experiences of working together and how hard it can be when teams work together the first time.

14. Term project (same teams) required students to create a decision support tool in Excel (VBA) that helps plan and execute a project - an "inception" task. This required the students to consciously think through time management of the term project itself.

15. Rubrics were used for the term project, including students creating their own rubric that was used to evaluate another team's project.

16. Three 'case days' were designed by the authors to provide an intense and deep experience regarding problem-solving, teamwork and project management. Benefits of case studies were employed [17]. The same case study theme was used for all three days, but the expected output increased with each iteration. The students were given the problem at 8:30 am it was due by 4:30 pm. There were no other courses, lectures, labs, or tutorials on these days. Furthermore, not everything they needed to know had been taught in class and they had to learn new material during these days. The students were expected to meet specific deadlines. The requirements were vague, the problem was ill-defined, and the students were given ample opportunity to make mistakes and learn from them. The student teams were assigned advisors (staff and faculty volunteers) who provided guidance throughout the day. The role of the advisors purposely diminished each case day. The teams eventually met requirements on their own, without any hand holding.

There were many other smaller points and mechanics to the course, but the above were the key cornerstones of MSCI 100. The students were also exposed to forecasting, inventory, queuing theory and other discipline related topics, but the exposure was delivered via the above methods. All methods were focused on the core concepts behind Management Engineering and were designed to facilitate the acquisition and development of the associated cognitive skills.

\subsection{The Class Pledge}

One key part of the course is the class pledge, a form of non-disclosure agreement, the class 'secret'. The class raises their hands and promised not to share class notes or details with future incoming classes. This agreement was 
done in the context of learning, both what was learned in the class and how it was learned. They realized that what they learned would not be possible if they had prior knowledge of the course design. The constructive failure mode does not work if the students know the game in advance. From what we can tell, the class thinks it is 'cool' and enjoy keeping this secret for the benefit of future cohorts. We could also tell that this caught the interest of potential students.

Of course, key aspects will be updated and revised in any event, but the amount of leakage will be reduced. Most importantly, the exercise got the students thinking about what they learned, how they learned it and how constructive failure works. They saw the benefit and embraced it. Minimizing sharing was one goal, but having the students value and understand how constructive failure works was a bigger goal.

\section{RESULTS AND DISCUSSION}

The students admitted being stressed initially because there was not math per se and no memorizing. However, they learned that repetition, feedback and carefully designed educational moments provided the recipe for true understanding of concepts and the ability to demonstrate this understanding. Everything in the course emphasized the process and the journey, not just the outcome.

The assessment tools used in the course increased in complexity and difficulty as the course progressed. This allowed the students to demonstrate increasing skill and understanding. The progression was evident in the majority of students' work. Part of the final assessment asked students to reflect on the course and their learning by doing a critical analysis. These answers provided insights into the changes in self-awareness and their thinking about learning. This was a book-end to the essay written in the first hour of the class in the first week asking them to self-reflect on their learning skills.

It is too early to tell if the lessons will be retained. Unfortunately, we do not have instruments and measurements from previous years that can be used to baseline against the effects. However, we plan to track this in future cohorts, as well as create a number of survey instruments to help us understand the course results.

Based on informal, casual observations and feedback from the students themselves, they seemed to have more confidence in their abilities at the post-secondary level after completing MSCI 100. They enhanced their core skills and their abilities related to learning and problemsolving for the first time. To actually be taught about learning, thinking, skill acquisition and expertise development was considered eye-opening and valuable.

For an unspecified reason, the incoming class failure rate for the whole term was less than one-third of the previous year and one-half of the best year to date. Why the sudden decrease in student failure? From what we could tell, the students felt better about themselves and this possibly translated to a better attitude and frame of mind when approaching other courses.

Perhaps most telling were comments made by the students on their course evaluations.

\subsection{Course Evaluation Results}

Student course evaluations are conducted in a prescribed way in all Faculty of Engineering courses. In their evaluations, students provide anonymous comments for instructors on components that worked well and areas that need improvement. Students in MSCI 100 were able to sense the instructor's enthusiasm and passion towards the subject. They also highlighted that he was approachable, helpful, understanding and cared about their learning by encouraging them to participate in discussions and to present their ideas in a safe classroom environment. Most of the students reported that they liked how the course was designed to foster their independent learning skills; this was evident to them during case days and hands-on projects where lots of ' $a h a$ ' learning moments were achieved. They enjoyed the open-ended, authentic nature of the project and how applicable the skills they learned are to their discipline and their career. Moreover, students liked having guest speakers and also noted that the TAs were very helpful.

In addition to what the students enjoyed in the course, some of them highlighted aspects that they thought needed improvement. They would have liked to be taught the information needed for the case days and the course project such as Excel and VBA in lecture or in the tutorials before being faced with the problem at hand. Although we recognize this and sympathize with the students, this is part of the learning model. A few students commented on the breadth of the course and mentioned that they would have preferred a more focused and indepth course. Unfortunately, the course is supposed to be a broad course and it is not possible to go in-depth on the topics. Some of the students were overwhelmed with the ambiguity of some of the course components and wanted to have a more typical course with more memorization while still appreciating their instructor's teaching philosophy. Without sounding callous, it was meant to be ambiguous and challenge the students' comfort zone.

One student wanted to shuffle the teams for the different course components, and this was the original plan but was changed due to their lack of prior experience with team dynamics. We now believe that it is very important to keep the teams intact for the majority of term projects. 


\subsection{Qualitative Feedback from Advisors}

The authors have solicited feedback from the team of advisors who mentored the students throughout the term during the case days. We asked about their comments on students' growth and development in terms of some basic skills such as team building, time management, developing project plans and reports as well as their professionalism.

The advisors witnessed the following:

- Multiple failure/recovery points in the term gave students the motivation to try new things in terms of organizing themselves, dividing work better, coming up with better ways to plan the days and share documents, etc. What they tried wasn't always successful, but at least they were attempting to try new things to deal with the challenges of the case days. Of course part of the challenge was that, although they were getting better at managing themselves, the assignments were also getting harder, so it seemed like they were always a step behind. They also had a hard time properly calibrating the amount of work needed for the status reports, schedules, etc. It was always either way too much detail, or not much at all.

- Teams progressed from "groups" to actual "teams". Throughout the case days, they learned each other's strengths, weaknesses, how their different personalities meshed together, effective communication, roles, etc. By Day 3, their team building had successfully given them a foundation to problem-solve effectively.

- Teaching their teammates was one of the main skills that they built as we always emphasized that every team member needed to be able to present all the work done by everyone, which was faced by students' resistance initially. However, they really valued it by the end of the course.

- On Day 1, the two teams were quite different in their evolution as a team. One had a member who comfortably jumped into the leader role and the others were happy to let him lead. Unfortunately, he led them down a path that didn't result in a positive outcome (in terms of their project) and so by the end of the day, a bit of frustration among the team members was sensed and the leader was flustered. The other team, however, didn't gel at the beginning of the day. There was someone who was trying to assert himself as a leader, but the others in the group didn't seem to accept him as a leader. This led to a bumpier start, but they seemed to have developed more as individuals, and as a team, throughout the day because they were having to actively work at it.

- Different advisors observed different time management skills in their teams, a couple of advisors noticed improvement in their teams' time management skills based on their stress level. On Day 1, groups were highly stressed and struggling to meet deadlines while by Day 3, teams were much more relaxed and they handed in their work well ahead of the deadlines. Another observer noticed that time management was still a big challenge for their teams.

- Generally the advisors stayed away from direct instructions and gave advice in the form of questions. On Day 1, this strategy seemed to incur more stress on the student teams since they were still working on building their soft skills and did not want to think the problem through on their own - they were hoping for some quick answers. By Day 3, they seemed to be more confident to take the open-ended advice and apply it to their work.

- On Day 1 the student teams created project plans because this was a mandated deliverable. However, it was evident to most advisors that minimal thought went into the plan and it was sensed that students had no real intention of referring back to their original plans during execution. Luckily, teams realized their mistake at the end of Day 1 and from then on, the time spent in developing and adhering to their project plans was much more rigorous.

\section{CONCLUSIONS AND NEXT STEPS}

The sole focus on concepts, both foundational understanding and application of professional skills, was a big shift in course design for MSCI 100. By moving away from math and memorization, the impact of the course could have a deeper impact on the students' ability to learn and contribute to their discipline. Although the first year concepts course is an important first step in the Management Engineering program, we will be working on ways to continue this educational growth.

Reinforcement exercises are planned for the rest of the students' academic terms - to remember, to practice and to reflect. We will also create a vertical learning experience for incoming students across the terms until they graduate. For both of these facets, we hope to track the different cohorts and execute surveys. In addition, we are investigating comments made by the students about their co-op interviews at the end of first year and how the concepts course helped them with their resumes and with the job hunt in general.

At the end of MSCI 100, we received feedback that the students were able to leverage the lessons at both the core level and application level to their benefit. As this is ultimately the goal of an introductory concepts course, we will pursue this strategy for future cohorts. It is time to move away from a teaching style used in $20^{\text {th }}$ century engineering programs, resist pervasive memorization in education, and create a professional skill foundation for students; and it starts in first year. Concepts only please. 


\section{Acknowledgements}

The authors would like to thank the various groups at University of Waterloo that supported the development and implementation of the Management Engineering concepts course: CTE, SSO, WATCACE, IDEAs Clinic and WCDE.

\section{References}

[1] Julia Pet-Armacost and Robert L. Armacost, "Enhancing communication and professional practice skills in an introductory engineering course," in Proc. Frontiers in Education Conf., FIE2003, vol. 2, pp.1015, 2003.

[2] Terrence J. Akai, "Engineering concepts: Introductory engineering courses should teach more than just rules and formulae," IEEE Potentials, vol. 5, no. 2, pp.1516,1986

[3] Sarah. J. Grigg and Lisa. C. Benson, "How does academic preparation influence how engineering students solve problems?," in Proc. Frontiers in Education Conf., FIE2012, (Seattle, WA; Oct. 2012), pp.1-6, 2012.

[4] Thomas J. Wenzel, "Using mistakes as learning opportunities," Analytical Chemistry, vol.74, no. 15, pp. 439A-440A, 2002.

[5] Management Sciences, "Bachelor of Applied Science (BASc) Management Engineering” [Online].

University of Waterloo. Available:

https://uwaterloo.ca/managementsciences/programs/bachelor-applied-science-bascmanagement-engineering [Accessed April 20, 2016].

[6] Centre for Teaching Excellence, "Welcome" [Online]. University of Waterloo. Available: https://uwaterloo.ca/centre-for-teaching-excellence/ [Accessed January 14, 2016].

[7] Student Success Office, "Student Success" [Online]. University of Waterloo. Available: https://uwaterloo.ca/student-success/ [Accessed January 22, 2016].

[8] Centre for the Advancement of Co-operative Education, "Welcome" [Online]. University of Waterloo. Available: https://uwaterloo.ca/centre- advancement-co-operative-education/ [Accessed April 14, 2016].

[9] Engineering IDEAs Clinic, "Home" [Online]. University of Waterloo. Available:

https://uwaterloo.ca/engineering-ideas-clinic/ [Accessed January 18, 2016].

[10] Waterloo Cases in Design Engineering, "Engineering Cases" [Online]. University of Waterloo. Available: https://uwaterloo.ca/engineering-cases/ [Accessed January 14, 2016].

[11] Donna E. Ellis, “Students' responses to innovative instructional methods: exploring learning-centered methods and barriers to change," Thesis for Doctor of Philosophy in Management Sciences. University of Waterloo, 2013.

[12] Pendergrass, N. A., Kowalczyk, R. E., Dowd, J. P., Laoulache, R. N., Nelles, W., Golen, J. A., and Fowler, E., "Improving first-year engineering education," Engineering Education, no. 90, pp. 3341, 2001.

[13] Golon, A. S. (2005). If you could see the way I think: A handbook for visual-spatial kids. Visual Spatial Resource.

[14] Van Lehn, K., Siler, S., Murray, C., Yamauchi, T., \& Baggett,W. B., "Why do only some events cause learning during human tutoring?," Cognition and Instruction, vol. 21, pp. 209-249, 2003.

[15] Scupin, R., "The KJ Method: A Technique for Analysing Data Derived from Japanese Ethnology," Human Organization, vol. 56, no. 2, pp. 233-237, 1997.

[16] Ishikawa, K. (1974) Guide to Quality Control, 1st Edition, Asian Productivity Organization.

[17] Oscar Nespoli, William Owen, Colin Campbell, and Steve Lambert, "Engineering case study implementation: Observations, results and perspectives," in Proc. ASEE American Society for Engineering Education Conf., (Austin, TX; 14-17 June 2009), 12 pp., 2009. 